\title{
Utilization of ICF in medical rehabilitation in Germany with a focus on cardiac rehabilitation
}

Tobias-Raphael Wenzel ${ }^{1}$, Matthias Morfeld ${ }^{1,2 *}$

'Institute for Healthcare research, Intervention, Therapy and Evaluation e.V., Stendal, Germany

*2University of Applied Sciences Magdeburg-Stendal, Rehabilitation Psychology, Stendal, Germany

\section{Article Info}

\section{Article Notes}

Received: January 11, 2018

Accepted: March 06, 2018

\section{*Correspondence:}

Prof. Dr. Matthias Morfeld, University of Applied Sciences

Magdeburg-Stendal, Rehabilitation Psychology, Stendal,

Germany;

E-mail: matthias.morfeld@hs-magdeburg.de

(C) 2018 Morfeld M. This article is distributed under the terms of the Creative Commons Attribution 4.0 International License.

\begin{abstract}
In Germany, the International Classification of Functioning, Disability and Health (ICF) is anchored in social law and it provides an important theoretical basis for rehabilitative action. Basically, there is an information deficit regarding the use of the ICF in rehabilitative practice in Germany. From the few publications available it can be concluded that the ICF in the practice of medical rehabilitation in Germany is used differently in nature and extent by social insurance agencies and service providers. There is a need for research to better map, support and develop the utilization of the ICF in the practice of medical rehabilitation in Germany.
\end{abstract}

\section{Introduction}

After more than 15 years of first mentioning ICF in German social legislation, it's use is now gaining momentum and ICF is being decisively named in new legislation as a reference model for needs assessment and also for the management of rehabilitation measures. The type and level of use of ICF vary between social insurance agencies and service providers as well as between the different areas of rehabilitation (e.g., vocational rehabilitation, medical rehabilitation, etc.). In the following article some important possibilities of utilization as well as the actual utilization of ICF in Germany in the field of medical rehabilitation, in particular cardiac rehabilitation will be presented.

\section{The ICF and medical Rehabilitation in Germany ${ }^{1}$}

The International Classification of Functioning, disability and Health (ICF) was founded in 2001 by the World Health Organization (WHO). The ICF substitutes the ICIDH (International Classification of impairments, disabilities and handicaps) which was based on a medical model comprehending disability as an attribute of affected Persons. In the ICIDH, neither environmental factors (e.g., the structural condition of the environment) nor personal factors were considered in terms of their effects and interactions for the Development of disability.

On a higher level, ICF is a tool for creating equal opportunities for people with disabilities ${ }^{4}$. Achieving this goal required the establishment of a new model. This Model had to be capable of

${ }^{1} \mathrm{~A}$ more detailed account of the use of the ICF in Germany can be found at 1-3 
capturing complex interactions between various factors that create disability and, ultimately, inequities in opportunities $^{5}$. ICF is based on this biopsychosocial model of the components of health. It allows the holistic view of a person, including it's health problem, it's contextual factors, and their dynamic interactions that ultimately manifest in it's functioning ${ }^{2}$ and disability ${ }^{4,5}$. In addition "ICF provides a standard language and conceptual basis for the definition and measurement of disability, and it provides classifications and codes" 7

Medical rehabilitation in Germany includes rehabilitative measures for people with post-acute health problems in the areas of neurology, orthopedics, cardiology, oncology, psychosomatics, addictions and injuries in case of accidents. In view of the specific requirements, medical rehabilitation necessarily is shaped by the interdisciplinary cooperation of many different professionals ${ }^{8-10}$. Furthermore, the references and methods of medical rehabilitation have changed. In Germany, for example, in recent years elements of vocational rehabilitation have increasingly been integrated into medical rehabilitation. There are some major Problems of medical rehabilitation Measures, for example regarding to the claim of personcentered needs assessments or the cross-clinical comparability of rehabilitation measures and outcomes.

In Germany, the application, initiation and implementation of a medical rehabilitation measure have been included in the Social Security Codes I, V, VI and IX. The term "function-related needs assessment" in the Social Security Code IX ( $§ 10$ SGB IX) is seen as a reference to the $\mathrm{ICF}^{11}$.

Although the ICF is mentioned explicitly in the Federal Law on Participation (Bundesteilhabegesetz), the implementation of the ICF at the level of social security agencies is left to their own discretion and is therefore largely non-binding ${ }^{12}$. Thus, on the one hand, there is a legally vaguely worded claim to use the ICF in medical rehabilitation, which is largely ignored by social insurance agencies $^{13}$. On the other hand, there are many efforts and examples of the utilization of the ICF both from the scientific side as well as in the practice of medical rehabilitation in Germany.

\section{Possibilities and requirements for the utilization of ICF in clinical practice}

To illustrate the utilization of ICF in clinical practice, WHO presents various options: „The ICF is relevant to many activities in clinical practice such as the consideration of health and functioning, setting goals, evaluating treatment outcomes, communicating with colleagues

\footnotetext{
${ }^{2}$ An interesting example from Italy for the field of cardiology show Racca et al. $^{6}$, who recorded the functioning in patients after a heart operation with the help of the ICF.
}

or the person involved. It provides a common language across clinical disciplines and with patients or clients. The ICF is complementary to the ICD - the global standard for classifying diseases - and, when used together, they present a full picture of the health status of an individual ${ }^{\text {"7 }}$.

Nonetheless, the WHO also places important and high demands on the utilization of ICF in practice. For medical rehabilitation, in addition to all other guidelines, particular attention must be paid to points 5 to 7 of the ICF ethical guidelines ${ }^{4}$. These include the need to inform patients about the purpose of using the ICF, the participation of patients in the process of classification and the holistic use of the ICF. In particular, the need for the holistic use of the ICF is critically discussed in the context of using ICF Core Sets, as they always contain only a section of the ICF selected by expert panels to simplify the use of the ICF in practice $^{14}$.

ICF sets out a framework for it's use with it's objectives and the guidelines and claims presented here, but leaves the development of suitable instruments to the addressed actors from research and practice. So far, this has led to a variety of different approaches with different methodological quality ${ }^{3}, 1$. At the same time, too little is known about the actual use of ICF in Germany ${ }^{1,15}$. The publications dealing with the use of ICF in the practice of medical rehabilitation in Germany show that in addition to the holistic philosophy and the understanding of health and functioning ${ }^{16}$ the following possibilities of utilization play a role:

- the common language in the sense of a unified conceptual system and understanding of the WHO's bio-psycho-social model for promoting interdisciplinarity ${ }^{2}$

- the use of the ICF as an assessment ${ }^{17,18}$

- goal setting ${ }^{4}{ }^{20-22}$ e.g. based on an assessment as well as the planning of rehabilitative services and the evaluation of corresponding outcomes ${ }^{23,24}$.

\section{Utilization of ICF in cardiac rehabilitation in Germany}

The bio-psycho-social model of the WHO is used in the field of cardiac rehabilitation in the form of a superordinate philosophy, e.g. about specialist literature ${ }^{25-27}$ and partly also in Disease Management Guidelines ${ }^{28}$ which can be seen as an indication for a simple biopsychosocial consideration of cardiac patients. ICF as a classification system, however, is not mentioned. Recent publications ${ }^{5}$ dealing with the ${ }^{3}$ For example, in many rehabilitation facilities self-created and often unvalidated ICF short-lists are being used for needs assessments while others use commercially distributed computer programs to do this.

${ }^{4}$ In a review of Constand et al. ${ }^{19}$ this question is being examined internationally.

${ }^{5}$ Although there are a few reviews ${ }^{35,}, 36,37$ that address this issue internationally, categories are used at a high level of abstraction, so the 
regular use of ICF in clinical practice are not available. However, there are some developments in the area of scientific projects.

Scheld et al. ${ }^{29}$ created a linkage between the 6-minute walk test (6MWT) -which is established in cardiac rehabilitation- and individual ICF codes in a study with a total of 113 people. "The 6MWT makes it possible to assess the performance of walking longer distances (ICF Code d4501) and thus help sports therapists to contribute to the assessment of Functional Health in an ICF-oriented concept of cardiac rehabilitation" 29 .

In a working group around M. Wirtz and J. Bengel in Freiburg, several instruments for cardiac rehabilitation were developed, e.g. for capturing anxiety ${ }^{30}$. The methodically sophisticated computer-adaptive assessment methods have the advantage that they can be used economically with a high degree of precision. This is made possible by the individual selection of the most informative items for each patient by means of a computer algorithm. The extent to which these methods are used in practice is not apparent from the available publications. The ICForiented, adaptive questionnaire for the assessment of mobility, self-care and domestic life developed by Farin et al. $^{31}$ is also a methodically sophisticated instrument whose routine use in the practice of cardiac rehabilitation Germany has no published indications.

With the work of Racca et $\mathrm{al} . .^{32}$ an extensive study on the development of an own Core Sets to detect the functioning of patients after cardiac surgery is available. The authors conclude: "The core set used to quantify important body functions and activities, including some areas that are generally considered insufficiently by healthcare professionals during cardiac rehabilitation, and document their improvement". Due to the lack of publications, however, no general statement can be made about the dissemination of practical application references arising from the presented instruments and approaches. This also applies to the already existing core sets for cardiac care in the acute ${ }^{33}$ and post-acute ${ }^{34}$ sector.

\section{Conclusions}

The ICF is used in various approaches in the medical and cardiac rehabilitation of service providers in Germany. However, there is insufficient knowledge of the nature and extent of this use. Both social security agencies and service providers are required by law to implement and actively use the ICF in their processes. They should observe the scientific standards, goals and ethical guidelines of the ICF both in the conception and in the use of appropriate approaches. For Patients and Healthcare workers, the use

concrete practice of use is not apparent. The question of what the ICF is used for can often be answered well with these findings, but not on how it is used in the specific case and how practical implementation problems are dealt with. of ICF provides a holistic view of patient-specific problems and capabilities as well as environmental and social resources and barriers. This provides comprehensive information in line with needs assessments as precondition for adequately configurated rehabilitation measures.

There is a need for research with regard to the systematic recording of the nature and extent of the use of the ICF in the practice of rehabilitation in Germany, e.g. in the form of empirical surveys, the monitoring of relevant publications and specialist congresses.

\section{Conflicts of interest Statement}

The authors, Tobias-Raphael Wenzel and Matthias Morfeld certify that they have NO affiliations with or involvement in any organization or entity with any financial interest (such as honoraria; educational grants; participation in speakers' bureaus; membership, employment, consultancies, stock ownership, or other equity interest; and expert testimony or patent-licensing arrangements), or non-financial interest (such as personal or professional relationships, affiliations, knowledge or beliefs) in the subject matter or materials discussed in this manuscript.

\section{Acknowledgement}

This research received no specific grant from any funding agency in the public, commercial, or not-for-profit sectors.

\section{References}

1. Wenzel T, Morfeld M. Die Internationale Klassifikation der Funktionsfähigkeit, Behinderung und Gesundheit (ICF)-Eine Expertise im AuftragderDeutschen GesellschaftfürRehabilitationswissenschaften e.V. (DGRW). Volume 10. Stendal; 2015.

2. Wenzel T, Morfeld M. Das biopsychosoziale Modell und die Internationale Klassifikation der Funktionsfähigkeit, Behinderung und Gesundheit. Bundesgesundheitsbl. 2016; 59: 1125-1132.

3. Wenzel T, Morfeld M. Nutzung der ICF in der medizinischen Rehabilitation in Deutschland: Anspruch und Wirklichkeit. Bundesgesundheitsblatt-Gesundheitsforschung-Gesundheitsschutz. 2017; 60: 386-393.

4. World Health Organization: International classification of functioning, disability and health. Geneva Switzerland. 2001.

5. Engel GL. The need for a new medical model: a challenge for biomedicine. Science. 1977; 196: 129-136.

6. Racca V, Di Rienzo M, Mazzini P, et al. ICF-based approach to evaluating functionality in cardiac rehabilitation patients after heart surgery. Eur J Phys Rehabil Med. 2015; 51: 457-468.

7. World Health Organization: How to use the ICF: A practical manual for using the International Classification of Functioning, Disability and Health (ICF). Geneva: WHO. 2013; 5.

8. Gutenbrunner C, Meyer T, Melvin J, et al. Towards a conceptual description of Physical and Rehabilitation Medicine. Journal of Rehabilitation Medicine. 2011; 43: 760-764.

9. Meyer T, Gutenbrunner C, Bickenbach J, et al. Towards a conceptual description of rehabilitation as a health strategy. Journal of Rehabilitation Medicin. 2011; 43: 765-769. 
10. Wade D. Rehabilitation--a new approach. Overview and Part One: the problems. Clin Rehabil. 2015; 29: 1041-1050.

11. Fuchs H. Die Anwendung der ICF im Rahmen des deutschen Sozialrechts. Forum C. 2013.

12. Schubert M, Schian M, Viehmeier S. Das Bundesteilhabegesetz. Bundesgesundheitsblatt-Gesundheitsforschung-Gesundheitsschutz. 2016; 59: 1053-1059.

13. Fuchs H. Zehn Jahre Sozialgesetzbuch IX-Eine kritische Bestandsaufnahme der Umsetzung. Soziale Sicherheit. 2011; 60: 208-213.

14. McIntyre A, Tempest S. Two steps forward, one step back? A commentary on the disease-specific core sets of the International Classification of Functioning, Disability and Health (ICF). Disability \& Rehabilitation. 2007; 29: 1475-1479.

15. Wiegand NM, Belting J, Fekete C, et al. All talk, no action?: the global diffusion and clinical implementation of the international classification of functioning, disability, and health. American journal of physical medicine \& rehabilitation / Association of Academic Physiatrists. 2012; 91: 550-560.

16. Alford VM, Ewen S, Webb GR, et al. The use of the International Classification of Functioning, Disability and Health to understand the health and functioning experiences of people with chronic conditions from the person perspective: a systematic review. Disabil Rehabil. 2015; 37: 655-666.

17. Queri S. ICF-Assessment in der Rehabilitation-wissenschaftlich und ökonomisch begründet. Das Gesundheitswesen. 2012; 74: A93.

18. Queri S. ICF-Assessment in der psychiatrischen Rehabilitation Begründung einer eigenständigen Rehabilitationsdiagnostik. Die Rehabilitation. 2014; 53: 230-236.

19. Constand MK, MacDermid JC. Applications of the International Classification of Functioning, Disability and Health in goal-setting practices in healthcare. Disabil Rehabil. 2014; 36: 1305-1314.

20. Fheodoroff K. Ziele setzen und Maßnahmen planen mit der ICF. Bern Huber. 2014.

21. Lohmann S, Decker J, Muller M, et al. The ICF forms a useful framework for classifying individual patient goals in post-acute rehabilitation. J Rehabil Med. 2011; 43: 151-155.

22. Wenzel $\mathrm{T}, \mathrm{Bahr} \mathrm{K}$, Froese $\mathrm{E}$, et al. Individualisierte Therapiezielvereinbarung in der Rehabilitation von Unfallverletzten. Deutsche Rentenversicherung Bund. Arbeit - Gesundheit Rehabilitation. 23. Rehabilitationswissenschaftliches Kolloquium. DRV Schriften. 2014; 225-226.

23. Grundmann J, Keller K, Bräuning-Edelmann M. [The practical application of the International Classification of Functioning, Disability and Health (ICF) in medical rehabilitation of psychiatric patients]. Die Rehabilitation. 2005; 44: 335-343.
24. Rauch A, Cieza A, Stucki G. How to apply the International Classification of Functioning, Disability and Health (ICF) for rehabilitation management in clinical practice. European journal of physical and rehabilitation medicine. 2008; 44: 329-342.

25. Hahmann HW. Kardiologische Rehabilitation. Herz. 2012; 37: 22-29.

26. Müller GA. Moderne Therapiekonzepte der kardiologischen Rehabilitation. Zeitschrift für Herz-, Thorax-und Gefä\textbackslashs schirurgie. 2011; 25: 187-192.

27. Reibis R, Schlitt A, Glatz J, et al. Rehabilitation bei Herzinsuffizienz. Rehabilitation. 2016; 55: 115-129.

28. Bundesärztekammer (Bäk) KBK AdwMF(: Nationale Versorgungsleitlinie Chronische Herzinsuffizienz. [http://www. awmf.org/uploads/tx_szleitlinien/ nvl-0061_S3_Chronische_ Herzinsuffizienz_2013-abgelaufen.pdf].

29. Scheld T, Völl M, Eckert HG, et al. ICF-orientierte Beurteilung der Leistungsfähigkeit in der kardiologischen Rehabilitation. B\&G Bewegungstherapie und Gesundheitssport. 2011; 27: 186-193.

30. Abberger B, Haschke A, Wirtz M, et al. Development and evaluation of a computer adaptive test to assess anxiety in cardiovascular rehabilitation patients. Archives of physical medicine and rehabilitation. 2013; 94: 2433-2439.

31. Farin E, Fleitz A, Frey C. Psychometric properties of an International Classification of Functioning, Disability and Health (ICF)-oriented, adaptive questionnaire for the assessment of mobility, self-care and domestic life. J Rehabil Med. 2007; 39: 537-546.

32. Racca V, Di Rienzo M, Mazzini P, et al. Icf-based approach to evaluating functionality in cardiac rehabilitation patients after heart surgery. European journal of physical and rehabilitation medicine. 2014.

33. Boldt C, Grill E, Wildner M, et al. ICF Core Set for patients with cardiopulmonary conditions in the acute hospital. Disability \& Rehabilitation. 2005; 27: 375-380.

34. Wildner M, Quittan M, Portenier L, et al. ICF Core Set for patients with cardiopulmonary conditions in early post-acute rehabilitation facilities. Disability \& Rehabilitation. 2005; 27: 397-404.

35. Cerniauskaite M, Quintas RUI, Boldt C, et al. Systematic literature review on ICF from 2001 to 2009: it's use, implementation and operationalisation. Disability and Rehabilitation. 2011; 33: 281-309.

36. Jelsma J. Use of the International Classification of Functioning, Disability and Health: a literature survey. Journal of Rehabilitation Medicine. 2009; 41: 1-12.

37. Maribo T, Petersen KS, Handberg C, et al. Systematic Literature Review on ICF From 2001 to 2013 in the Nordic Countries Focusing on Clinical and Rehabilitation Context. J Clin Med Res; 2016; 8: 1-9. 